\title{
MicroRNA as Biomarkers for Platelet Function and Maturity in Patients with Cardiovascular Disease
}

\author{
Oliver Buchhave Pedersen ${ }^{1,2(0)}$ Erik Lerkevang Grove ${ }^{2,30}$ Steen Dalby Kristensen ${ }^{2,3}$ \\ Peter H. Nissen ${ }^{1,3}$ Anne-Mette Hvas ${ }^{1,3(0)}$
}

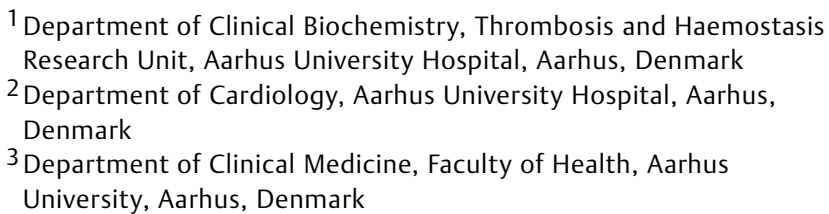

Address for correspondence Oliver Buchhave Pedersen, MD, Department of Clinical Biochemistry, Thrombosis and Haemostasis Research Unit, Aarhus University Hospital, Palle Juul-Jensens Boulevard 99, 8200 Aarhus N, Denmark (e-mail: olihped@gmail.com).

\begin{abstract}
Keywords

- MicroRNAs

- biomarker

- platelet function test

- prognosis

- cardiovascular disease
\end{abstract}

Patients with cardiovascular disease (CVD) are at increased risk of suffering myocardial infarction. Platelets are key players in thrombus formation and, therefore, antiplatelet therapy is crucial in the treatment and prevention of CVD. MicroRNAs (miRs) may hold the potential as biomarkers for platelet function and maturity. This systematic review was conducted using the guidelines of Preferred Reporting Items for Systematic Reviews and Meta-Analyses (PRISMA). To identify studies investigating the association between miRs and platelet function and maturity in patients with CVD, PubMed and Embase were searched on October 13 and December 13, 2020 without time boundaries. Risk of bias was evaluated using a standardized quality assessment tool. Of the 16 included studies, 6 studies were rated "good" and 10 studies were rated "fair." In total, 45 miRs correlated significantly with platelet function or maturity (rho ranging from -0.68 to 0.38 , all $p<0.05$ ) or differed significantly between patients with high platelet reactivity and patients with low platelet reactivity ( $p$-values ranging from 0.0001 to 0.05 ). Only four miRs were investigated in more than two studies, namely miR-223, miR-126, miR-21 and miR-150. Only one study reported on the association between miRs and platelet maturity. In conclusion, a total of 45 miRs were associated with platelet function or maturity in patients with CVD, with miR-223 and miR-126 being the most frequently investigated. However, the majority of the miRs were only investigated in one study. More data are needed on the potential use of miRs as biomarkers for platelet function and maturity in CVD patients.

\section{Introduction}

Cardiovascular diseases (CVDs) account for a considerable percentage of morbidity and mortality. ${ }^{1,2}$ Platelets are essential for repairing endothelial damage and maintaining primary haemostasis. ${ }^{3}$ However, due to plaque rupture and

received

February 6, 2021

accepted after revision

April 7, 2021

published online

June 6, 2021 platelet-mediated thrombosis, patients with CVD may experience myocardial infarction. ${ }^{4-6}$ Accordingly, platelet inhibitors are considered to be the cornerstone in prevention and treatment of CVD caused by atherosclerosis. ${ }^{7-9}$ However, despite prophylactic antiplatelet therapy, patients remain at $\begin{array}{ll}\text { C } 2021 . \text { Thieme. All rights reserved. } & \text { DOI https://doi.org/ } \\ \text { Georg Thieme Verlag KG, } & \text { 10.1055/s-0041-1730375 } \\ \text { Rüdigerstraße 14, } & \text { ISSN 0340-6245. }\end{array}$

70469 Stuttgart, Germany 
high risk of recurrent cardiovascular events. ${ }^{10-13}$ The insufficient effect of platelet inhibitors is probably caused by multiple mechanisms such as genetic variability, drug interactions, and increased platelet turnover. ${ }^{14,15}$ Hence, there is a great need for biomarkers to identify these high-risk patients. Altered platelet function and the amount of newly formed platelets, termed immature platelets, are of great importance for the risk of recurrent cardiovascular events. ${ }^{15,16}$ Immature platelets, contrary to mature platelets, contain ribonucleic acid (RNA) providing the ability to produce proteins important for platelet function. ${ }^{17-19}$

MicroRNAs (miRs) are small noncoding RNA ${ }^{20}$ involved in gene regulation ${ }^{21,22}$ and present in many cells including platelets. ${ }^{23}$ Owing to their stability in the circulation, miRs may hold a potential as biomarkers. ${ }^{21}$ Previous studies indicate that miRs contribute to the regulation of both platelet formation ${ }^{24,25}$ and platelet function. ${ }^{26,27}$

The objective of this systematic review was to summarize and discuss the current literature on miRs potentially associated with platelet function and maturity in patients with CVD.

\section{Methods}

\section{Study Design and Search Strategy}

The systematic review was conducted using a predefined protocol following the guidelines of Preferred Reporting items for Systematic Reviews and Meta-analyses (PRISMA), ${ }^{28}$ and was registered in PROSPERO International Prospective Register of Systematic Reviews (https://www.crd.york.ac.ul/prospero/;Record-ID: 220095). A systematic search of all original research without time boundaries was performed in the databases PubMed/Medline and Embase/Ovid on October 13, 2020 and updated on December 13, 2020. Additional articles were found in reference lists of identified studies and by using the "shared references" search in the Web of Science database. Authors of identified appropriate studies were contacted to obtain additional data not reported.

The PubMed search string was as follows: ((((micrornas) AND $(((()(((($ blood platelets) OR ("platelet function"[All Fields])) OR ("platelet function tests"[MeSH Terms])) OR ("platelet activation"[MeSH Terms])) OR (platelet aggregation)) OR (platelet adhesiveness)) OR (mean platelet volume)) OR ("immature platelets"[All Fields])) OR ("immature platelet fraction"[All Fields])) OR ("immature platelet count”[All Fields]))) AND (((cardiovascular disease) OR (arteriosclerosis)) OR (“coronary artery disease"[MeSH Terms]))) NOT (("Animals"[Mesh]) NOT ("Humans”[Mesh]))). The Embase search string was as follows: 'microrna'/exp AND ('thrombocyte'/exp OR 'thrombocyte function'/exp OR 'thrombocyte adhesion'/exp OR 'thrombocyte aggregation'/ exp OR 'thrombocyte activation'/exp OR 'mean platelet volume'/exp OR 'immature platelet count'/exp OR 'immature platelet count' OR 'immature platelet fraction'/exp OR 'immature platelet fraction') AND ('cardiovascular disease'/exp OR 'cardiovascular disease' OR 'coronary artery disease'/exp OR 'coronary artery disease') NOT (('animal'/exp OR 'animal' OR ‘nonhuman'/exp OR ‘nonhuman') NOT (('animal'/exp OR 'animal' OR 'nonhuman'/exp OR 'nonhuman') AND ('human'/ exp OR 'human'))) AND [english]/lim AND ('article'/it OR 'article in press'/it OR 'review'/it).

\section{Eligibility Criteria and Study Selection}

Inclusion and exclusion criteria were pre-specified before the literature search. Inclusion criteria were the following: (1) studies examining patients with CVD; (2) studies examining the expression of miRs; and (3) studies presenting original data evaluating platelet function (determined by adhesion, activation or aggregation), maturity (determined by immature platelet count, immature platelet fraction or mean platelet volume [MPV]) or both. Exclusion criteria were the following: (1) letters, conference abstracts, editorials and letters without original data, guidelines, meta-analysis or comments without original data; (2) case reports with less than five patients; (3) animal and in vitro studies; and (4) non-English publications.

After removing duplicates, 20 random abstracts were distributed between two authors, OBP and $\mathrm{AMH}$, and screened for relevance to evaluate inclusion criteria. The remaining abstracts were screened by OBP. Studies considered relevant or unclear were assessed in full-text review. By choosing a random sample of 10 of the full text, the study selection was tested independently by OBP and AMH. All disagreements were discussed by all authors to reach consensus. OBP performed the rest of the study selection.

\section{Data Extraction}

Data extraction was performed by OBP and verified by AMH.

Measurements of platelet function were reported as platelet activation or platelet aggregation. Platelet activation analyses included measurements of soluble markers of platelet activation (expression of activation-dependent platelet markers) and platelet aggregation as functional analyses. Platelet maturity was reported as MPV. As immature platelets are larger than mature platelets, increasing MPV values correspond to an increased number of immature platelets. ${ }^{16,17,29}$

To evaluate the potential risk of bias, OBP and $\mathrm{AMH}$ independently evaluated each study using the standardized quality assessment tool for observational cohort and crosssectional studies from the National Heart, Lung, and Blood Institute of the National Institutes of Health rating the quality of studies as good, fair or poor. ${ }^{30}$ In accordance with most of the included studies, the ranking was performed with platelet function or maturity as exposure and the miR levels as outcome. Disagreements were discussed to reach consensus.

\section{Results}

-Fig. 1 shows the inclusion and exclusion flow diagram. After removal of duplicates, 335 records were screened by title and abstract. During this screening process, 297 records were excluded and the remaining 38 records were assessed for eligibility in full-text papers. Among these, 22 records were excluded in accordance with the eligibility criteria, leaving 16 studies for inclusion in the systematic review. 


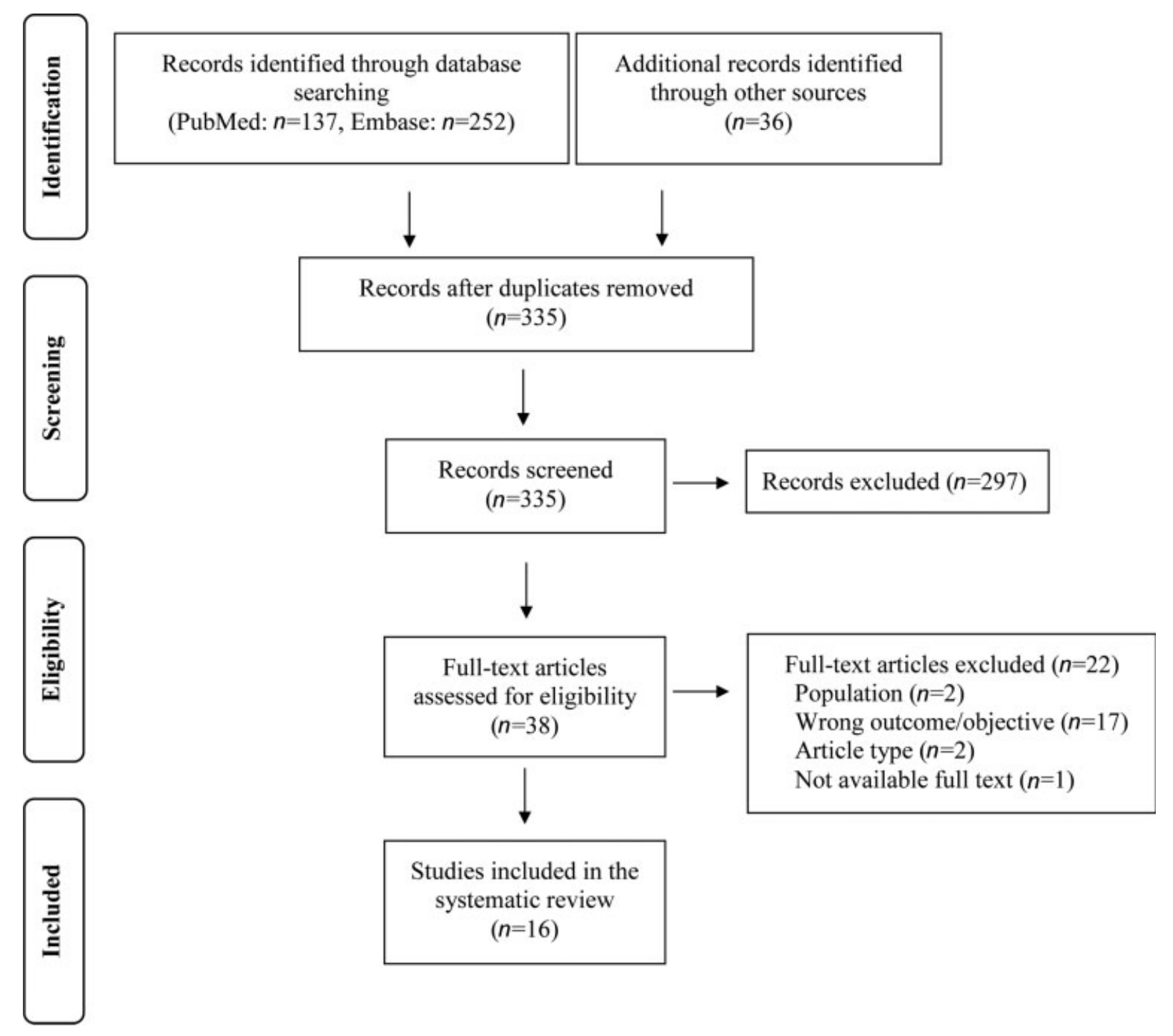

Fig. 1 Flow diagram of the systematic literature search.

\section{miR Analyses}

- Table 1 summarizes characteristics of the miR analyses in the included 16 studies. One study used blood cells, ${ }^{31} 1$ study used leukocyte suspension ${ }^{32}$ and 14 studies used plasma samples. ${ }^{33-46}$ Among the studies using plasma samples, seven studies used platelet-rich plasma (PRP), ${ }^{34,36,37,39,42,43,46}$ whereas two studies used plateletpoor plasma (PPP). ${ }^{33,35}$

To compensate for potential analytical variations, ${ }^{47}$ all studies used normalization strategies of the measured miRs. Four studies used high-throughput sequencing to investigate a large number of miRs followed by reverse transcriptase quantitative polymerase chain reaction (RT-qPCR) of a selected number of miRs. ${ }^{33,39,44,46}$ The remaining 12 studies used only RT-qPCR to investigate pre-selected miRs. ${ }^{31,32,34-38,40-43,45}$

\section{Subgroups, Laboratory Analyses, and Treatment}

In 12 of 16 included studies, the patient cohort was divided into subgroups. ${ }^{32-37,39,42-46}$ The methods and cut-offs employed to define subgroups varied between studies.
Therefore, we decided to define the patient cohorts as having either high platelet reactivity (HPR) or low platelet reactivity (LPR) corresponding to low and high antiplatelet response.

To categorize patients, 9 of 16 included studies used platelet aggregation measurements (multiple electrode aggregation [MEA], light transmission aggregation [LTA] or optical aggregation), $32,35,37-40,43,44,462$ studies used platelet reactivity index (PRI) by vasodilator-stimulated phosphoprotein (VASP) measurements, ${ }^{36,45} 4$ studies used a combination of these ${ }^{33,34,41,42}$ and 1 study used MPV. ${ }^{31}$

In five of the included studies, blood samples were obtained at different time points. ${ }^{33,34,37,40,43}$ The results were only presented if the studies also investigated the corresponding association between miRNA and platelet function. We denominated the first blood sample as baseline and the following blood samples were named after the number of days they were taken after the baseline sample.

All included studies, except one, ${ }^{31}$ provided information on antiplatelet therapy. In studies on patients with acute coronary syndrome (ACS), all patients were treated according to guidelines with dual antiplatelet inhibitors consisting 
Table 1 MicroRNA analyses in the 16 included studies

\begin{tabular}{|c|c|c|c|c|c|c|c|}
\hline Study & Anticoagulant & Sample & Further preparation & RNA extraction & Sequencing & RT-qPCR & Normalization \\
\hline Becker et $\mathrm{al}^{33}$ & NA & PPP & NA & Perfect pure + miRNeasy & Yes & Yes & $\begin{array}{l}\text { Endogenous } \\
\text { miRs }\end{array}$ \\
\hline Binderup et $\mathrm{al}^{35}$ & EDTA & PPP & 1 cycle of centrifugation & Nucleospin & No & Yes & miR-39 \\
\hline Chen et $\mathrm{al}^{36}$ & Citrate & PRP & $\begin{array}{l}1 \text { cycle centrifugation + } \\
\text { anti-CD45 beads }\end{array}$ & NA & No & Yes & U6 \\
\hline Chen et $\mathrm{al}^{37}$ & NA & PRP & Centrifugation ${ }^{\mathrm{a}} \mathrm{NA}$ cycles & High pure & No & Yes & $\mathrm{U} 44+\mathrm{U} 48$ \\
\hline Chyrchel et $\mathrm{al}^{38}$ & EDTA & Plasma & NA & mirVana & No & Yes & miR-16 \\
\hline Ding et $\mathrm{al}^{39}$ & Citrate & PRP & 2 cycles of centrifugation & TRIzol & Yes & Yes & miR-16 \\
\hline Jäger et al ${ }^{40}$ & EDTA & Plasma & NA & miRNeasy & No & Yes & miR-39 \\
\hline Kaudewitz et al ${ }^{41}$ & Citrate & Plasma & 2 cycles of centrifugation & miRNeasy & No & Yes & U6 \\
\hline Li et $\mathrm{al}^{31}$ & EDTA & Blood cells & NA & TRIzol & No & Yes & U6 \\
\hline Li et $\mathrm{al}^{34}$ & EDTA & PRP & 3 cycles of centrifugation & miRNeasy & No & Yes & R43 \\
\hline Peng et $\mathrm{al}^{43}$ & Citrate & PRP & Anti-CD45 beads & mirVana & No & Yes & U6 \\
\hline Shi et al ${ }^{42}$ & Citrate & PRP & Anti-CD45 beads & TRIzol + mirVana & No & Yes & U6 \\
\hline Tang et $\mathrm{al}^{44}$ & EDTA & Plasma & 1 cycle of centrifugation & mirVana & Yes & Yes & miR-39 \\
\hline Xie et $\mathrm{al}^{32}$ & NA & Leukocytes & NA & TRIzol + miRNeasy & No & Yes & U6 \\
\hline Zhang et al ${ }^{45}$ & Citrate & Plasma & NA & RNAiso & No & Yes & $\begin{array}{l}\text { Human- } \\
\text { 5s-rRNA }\end{array}$ \\
\hline Zufferey et al ${ }^{46}$ & EDTA & PRP & 1 cycle of centrifugation & mirVana & Yes & Yes & $\begin{array}{l}\text { Internal } \\
\text { controls }\end{array}$ \\
\hline
\end{tabular}

Abbreviations: EDTA, Ethylenediaminetetraacetic acid; NA, not available; PPP, platelet-poor plasma; PRP, platelet-rich plasma; RT-qPCR, reverse transcriptase quantitative polymerase chain reaction.

${ }^{a}$ Centrifugation until leucocyte to platelet ratio $<0.4 \%$.

of aspirin and clopidogrel preceded by loading dose (- Table 2). ${ }^{33,34,38,39,42,43,45}$ In the studies on patients with coronary artery disease (CAD), the antiplatelet treatment consisted of either aspirin monotherapy or dual antiplatelet therapy with aspirin plus adenosine diphosphate (ADP) inhibitor (- Table 3). ${ }^{32,33,36,37,40,41,44}$ In the two studies examining patients with intermittent claudication ${ }^{35}$ or patients with symptomatic atherothrombotic diseases, ${ }^{46}$ all patients were treated with aspirin monotherapy (-Table 4).

\section{Study Characteristics}

The included studies were divided into three groups based on patient characteristics. - Table 2 presents studies investigating ACS patients $(n=6))^{34,38,39,42,43,45}$-Table 3 presents studies investigating stable CAD patients $(\boldsymbol{n}=7) .^{31,32,36,37,40,41,44}$ - Table 4 presents studies investigating other patient groups including both ACS and CAD patients $(n=1),{ }^{33}$ patients with intermittent claudication $(n=1)^{35}$ and patients with symptomatic atherothrombotic diseases defined as CAD, ischemic cerebrovascular disease and/or peripheral artery disease $(n=1) .{ }^{46}$ In the studies using sequencing to investigate a variety of miRs, ${ }^{33,39,44,46}$ only those miRs presented with corresponding association with platelet function or used in further analyses are presented in the tables. Seven studies reported miRs as the miR family without further specifications. ${ }^{34,38,40-43,45}$ Nine stud- ies further specified the investigated $\mathrm{miR}$, that is $3 \mathrm{p}$ - or $5 \mathrm{p}$ arm of the particular miR..$^{31-33,35-37,39,44,46}$ Therefore, if a particular miR was reported in various ways, the tables present the overall miR family. A comprehensive overview of miRs including the number of studies and the corresponding patient groups is available in the -Supplementary Table S1 (available in the online version). The qualitative assessment of the included studies is also indicated in - Tables 2,3,4. Six studies were rated good, ${ }^{31,39,42-45} 10$ studies fair ${ }^{32-38,40,41,46}$ and no studies were rated poor. A detailed review of the ratings including the related questions is available in the - Supplementary Table $\mathbf{S 2}$ (available in the online version).

\section{Expression Levels of miRs and Platelet Function and Maturity}

Out of 58 investigated miRs, 45 miRs correlated significantly with platelet function or maturity (rho ranging from -0.68 to 0.38 , all $p<0.05$ ) or differed significantly between HPR patients and LPR patients ( $p$-values ranging from 0.0001 to 0.05 ), whereas 13 miRs showed no association with platelet function or maturity (-Table 5 ).

Of the miRs significantly associated with platelet function, 10 of 45 were investigated in more than one study (-Fig. 2). The most frequently investigated miRs were miR-223 $(n=9),{ }^{32,34,37,38,40-43,45} \mathrm{miR}-126(n=5),{ }^{33,34,40,41,44} \mathrm{miR}-$ $21(n=5)^{33,34,40,43,44}$ and miR-150 $(n=4),{ }^{34,40,41,46}$ whereas 


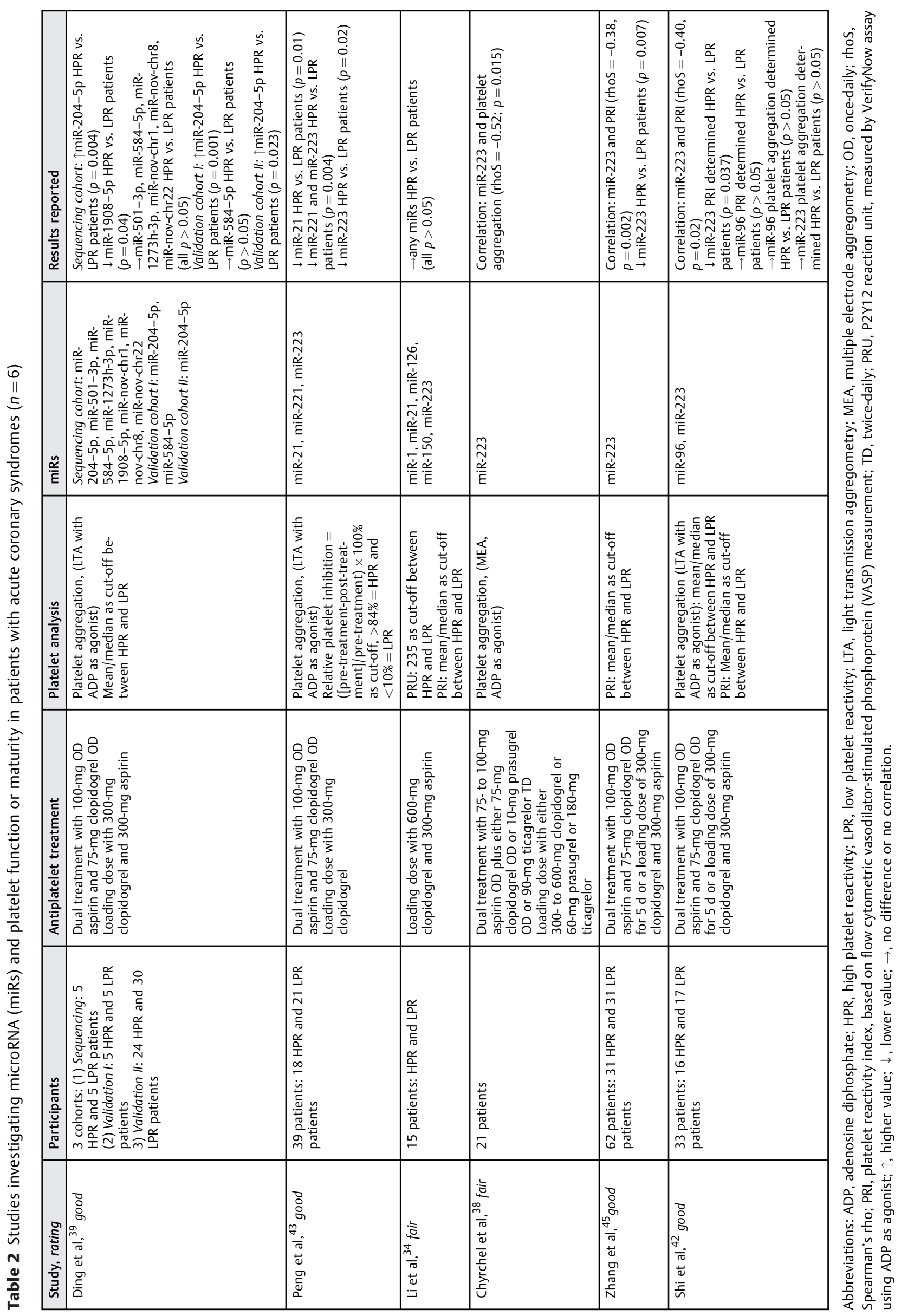




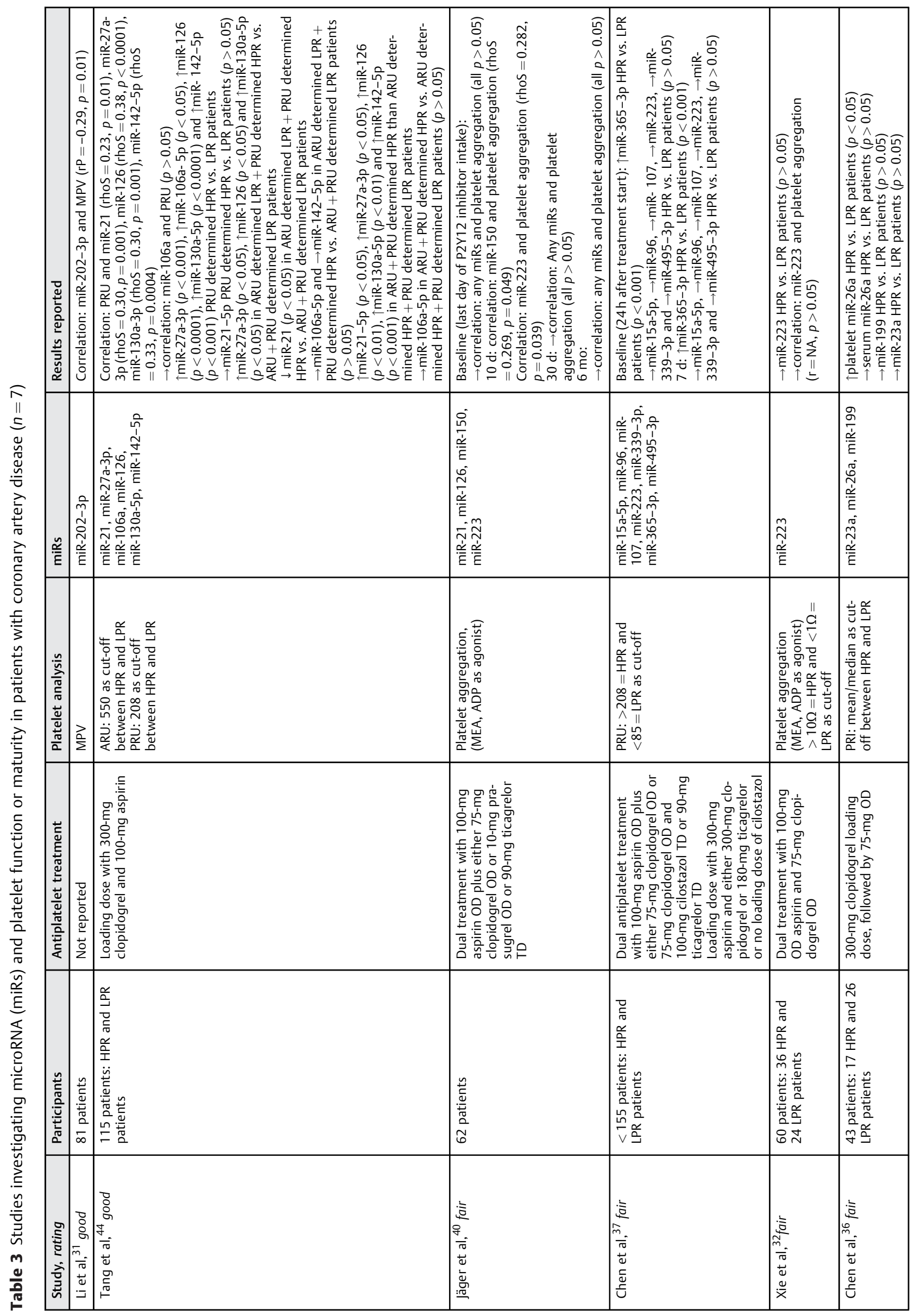

Thrombosis and Haemostasis Vol. 122 No. 2/2022 @ 2021. Thieme. All rights reserved. 


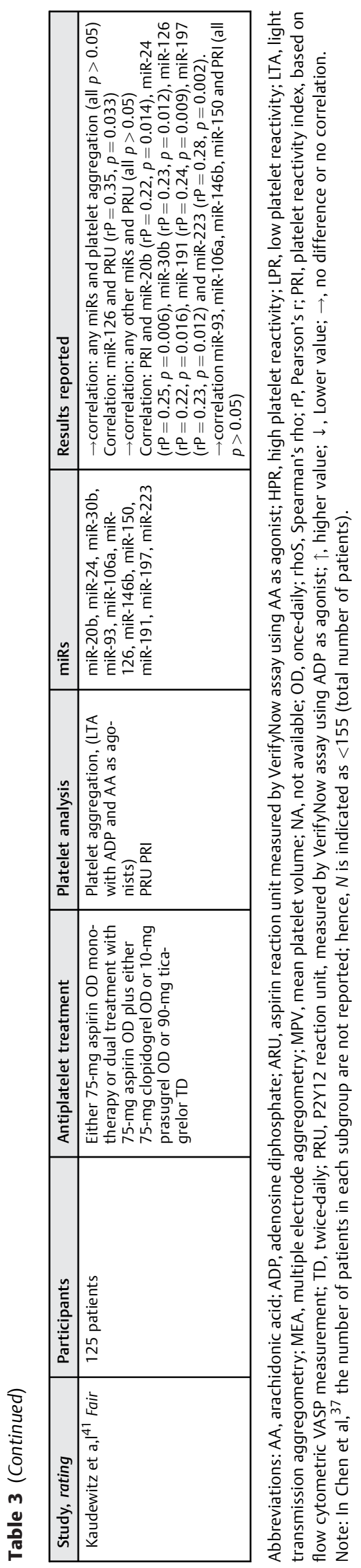

miR-1, 34,46 miR-93, ${ }^{33,41}$ miR-96, ${ }^{37,42}$ miR-106a, ${ }^{41,44}$ miR$197^{33,41}$ and miR-204-5 $\mathrm{p}^{39,46}$ were investigated in two studies only. Only one study reported on platelet maturity by measurements of MPV. ${ }^{31}$

miR-223

Significant negative associations were found between miR223 and platelet function in four of the five studies including ACS patients, ${ }^{38,42,43,45}$ whereas Li et al reported no association between miR-223 and platelet function in ACS patients. ${ }^{34}$ On the contrary, among four studies including only CAD patients, two studies reported positive correlations between miR-223 and platelet function, ${ }^{40,41}$ whereas two studies found no association. ${ }^{32,37}$

miR-126

Five studies investigated miR-126 and platelet function. In a study including ACS patients only, no association was found. ${ }^{34}$ In patients with CAD only, two studies reported positive correlations between miR-126 and platelet function, ${ }^{41,44}$ whereas one study demonstrated no association. ${ }^{40}$ Becker et al included both ACS and CAD patients and found that miR-126 correlated negatively with platelet function in the target cohort consisting of ACS patients. ${ }^{33}$ However, in the validating cohorts of CAD patients, a positive correlation with platelet function was found. ${ }^{33}$

miR-21

In the two studies of miR-21 in ACS patients, Peng et al reported lower miR-21 in HPR patients than LPR patients, ${ }^{43}$ whereas Li et al found no association between miR-21 and platelet function. ${ }^{34}$ In studies of CAD patients, one demonstrated a positive correlation between miR-21 and platelet function, ${ }^{44}$ whereas another study reported no association. ${ }^{40}$ Becker et al included both ACS and CAD patients and found that miR-21 negatively correlated with platelet function in the sequencing cohort of ACS patients, but not in the target cohort of ACS patients or in the validating cohorts consisting of CAD patients. ${ }^{33}$

miR-150

miR-150 was investigated in four studies. ${ }^{34,40,41,46}$ No association was found in ACS patients. ${ }^{34}$ In CAD patients, Jäger et al found a positive correlation between miR-150 and platelet function, ${ }^{40}$ whereas Kaudewitz et al found no association. ${ }^{41}$ In patients with symptomatic atherothrombotic diseases, miR150 was lower in HPR patients than in LPR patients. ${ }^{46}$

miRs Investigated in Two Studies

miR-1 was only investigated in one study of ACS patients where no association with platelet function was found. ${ }^{34}$ In patients with symptomatic atherothrombotic diseases, miR1 was found to be higher in HPR patients than in LPR patients. $^{46}$

In two studies of CAD patients, Tang et al reported miR106a to be higher in HPR patients than LPR patients, ${ }^{44}$ whereas Kaudewitz et al found no association between miR-106a and platelet function. ${ }^{41}$ 


\begin{tabular}{|c|c|c|}
\hline 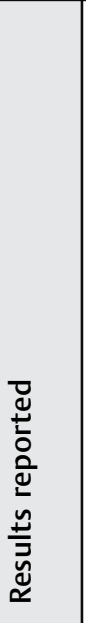 & 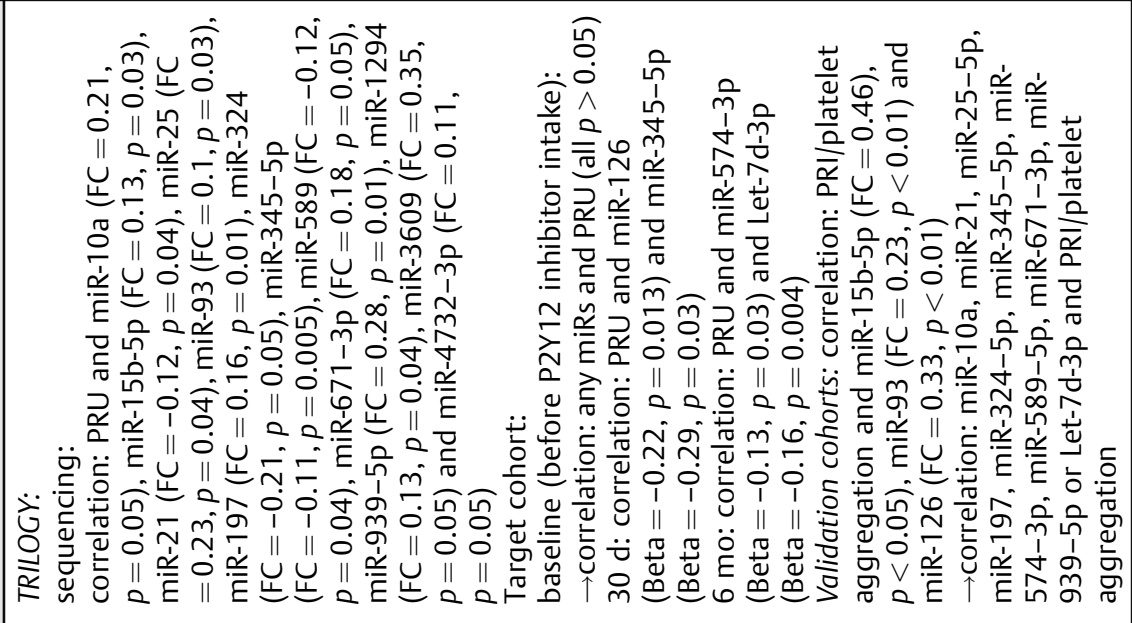 & 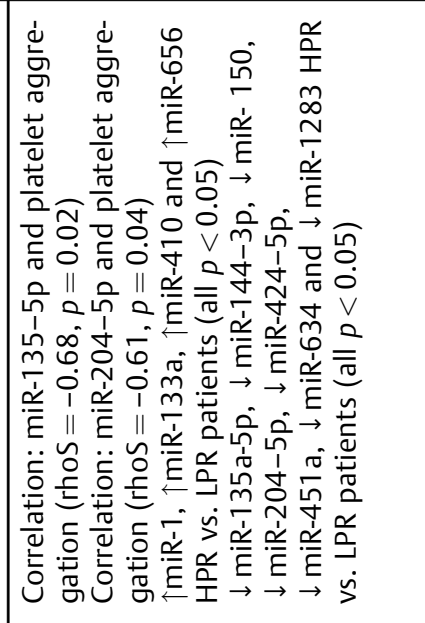 \\
\hline$\stackrel{\widetilde{\mathscr{E}}}{\underline{\mathrm{E}}}$ & 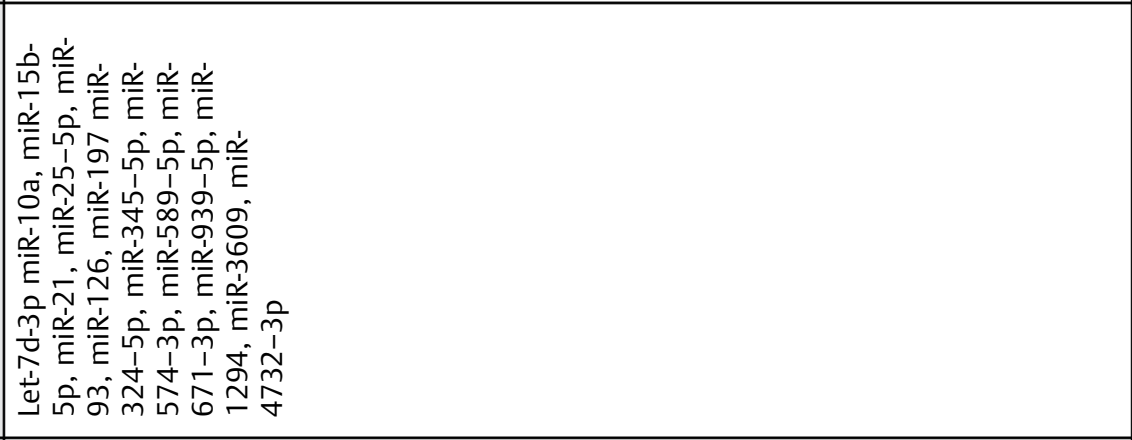 & 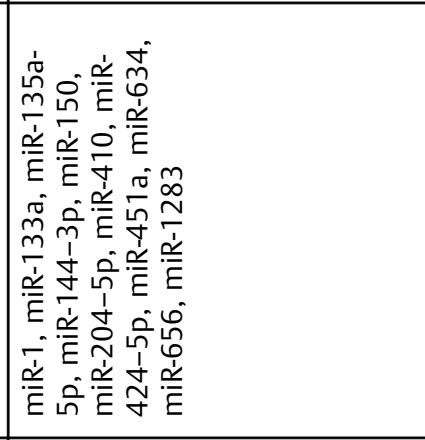 \\
\hline 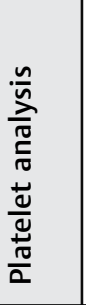 & 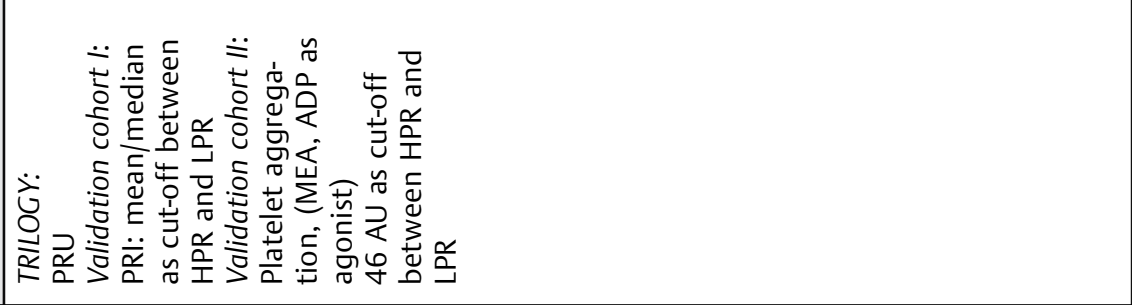 & 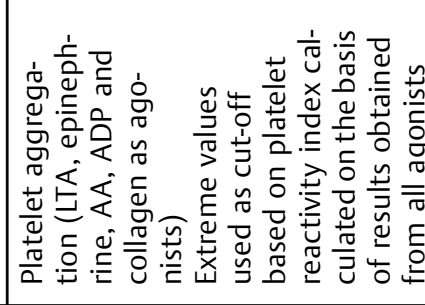 \\
\hline 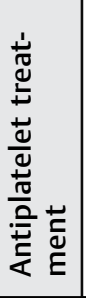 & 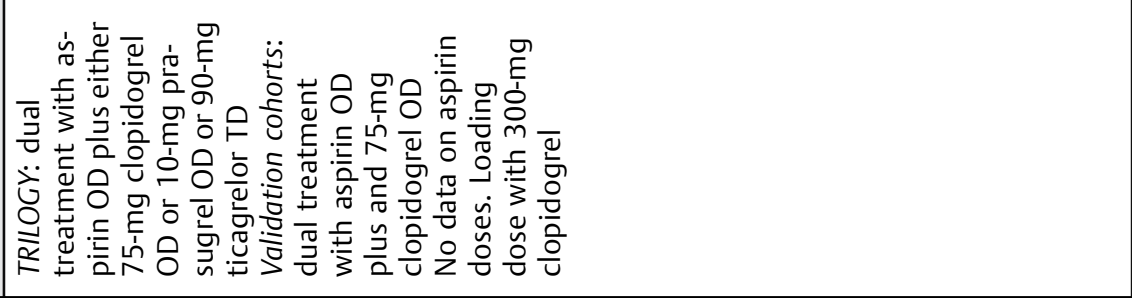 & 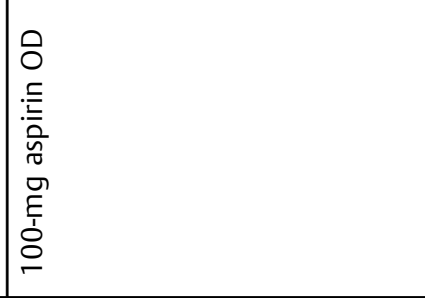 \\
\hline 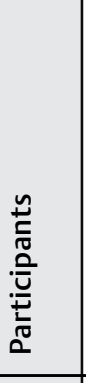 & 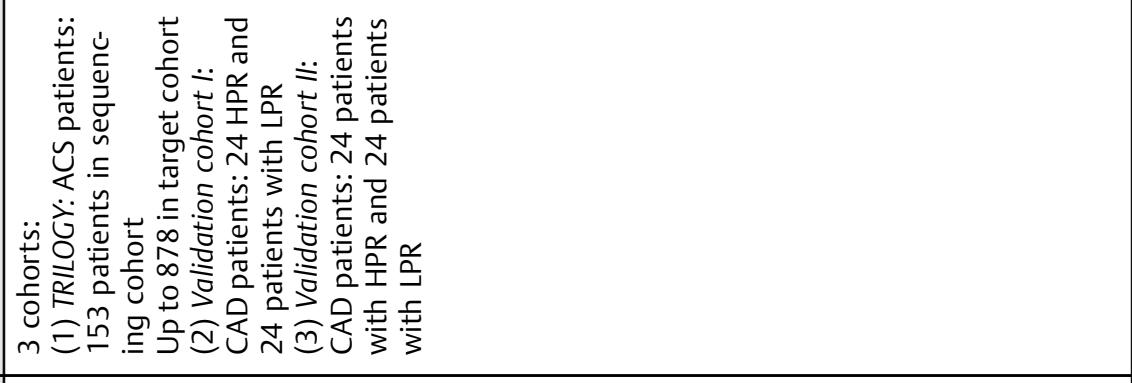 & 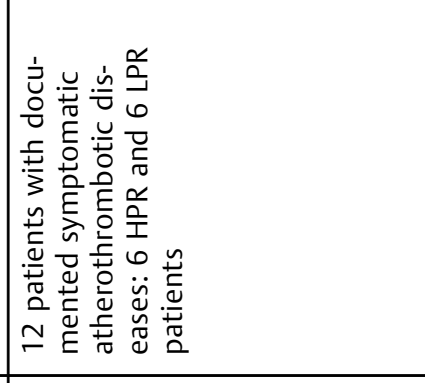 \\
\hline 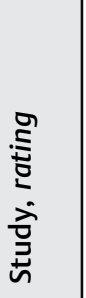 & 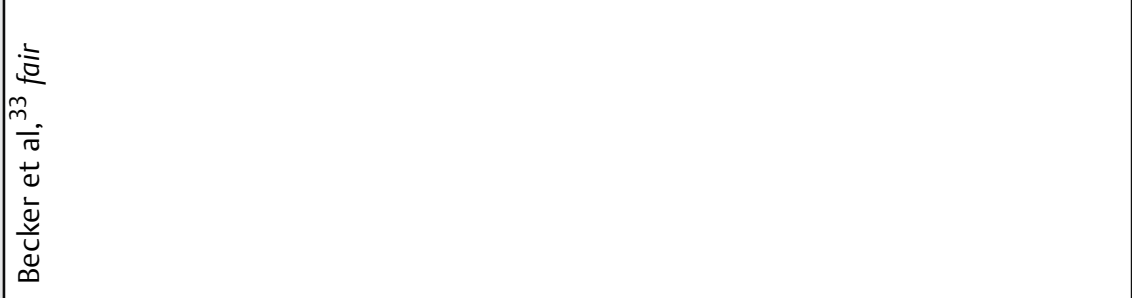 & 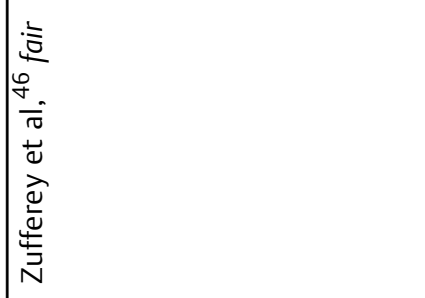 \\
\hline
\end{tabular}


In a study examining both ACS and CAD patients, miR-197 correlated positively with platelet function in the sequencing cohort of ACS patients, but neither in the target cohort of ACS patients nor in the validating cohorts consisting of CAD patients. $^{33}$ In CAD patients, miR-197 correlated positively with platelet function. ${ }^{41}$

miR-204-5p was higher in HPR patients than in LPR patients in a cohort of ACS patients, ${ }^{39}$ whereas in patients with symptomatic atherothrombotic diseases, miR-204-5p was lower in HPR patients than in LPR patients and further correlated negatively with platelet function. ${ }^{46}$

Kaudewitz et al determined miR-93 in a cohort of CAD patients and reported no association with platelet function. ${ }^{41}$ However, in the study by Becker et al, examining both ACS patients and CAD patients, miR-93 correlated positively with platelet function in both patient groups. ${ }^{33}$

With regard to miR-96, both the study of ACS patients and the study of CAD patients reported no association between miR-96 and platelet function. ${ }^{37,42}$

miRs Investigated in One Study Only

Of the $35 \mathrm{miRs}$ only investigated in one study, 2 miRs were investigated in ACS patients, ${ }^{39,43} 12 \mathrm{miRs}$ in CAD patients, ${ }^{36,37,41,44} 12$ in both ACS and CAD patients, ${ }^{33} 2$ in patients with intermittent claudication and healthy individuals, ${ }^{35}$ and 9 in patients with symptomatic atherothrombotic diseases. ${ }^{46}$ In ACS patients, miR-221 and miR-1908-5p were lower in HPR patients than in LPR patients. ${ }^{33,39,43}$ In CAD patients, miR-20b, miR-24, miR-27a-3p, miR-30b, miR-130a5p, miR-142-5p and miR-191 demonstrated a positive correlations with platelet function, and miR-26a, miR-27a-3p, miR-130a-5p, miR-142-5p and miR-365-3p were higher in HPR than in LPR patients. ${ }^{36,37,41,44}$ In the study by Becker et al, examining both ACS and CAD patients, let-7d-3p, miR324-5p, miR-345-5p, miR-574-3p and miR-589-5p correlated negatively, whereas miR-10a, miR-15b-5p, miR-25-5p, miR-671-3p, miR-939-5p, miR-1294, miR-3609 and miR4732-3p correlated positively with platelet function in ACS patients but not in CAD patients. ${ }^{33}$ In patients with intermittent claudication, miR-92a correlated positively with platelet function when pooling patients and healthy individuals, but not exclusively in patients. ${ }^{35}$ In addition, miR-92a was higher in HPR patients than in LPR patients. ${ }^{35}$ In patients with symptomatic atherothrombotic diseases, miR-135a-5p correlated negatively with platelet function, miR-133a, miR-410 and miR-656 were higher in HPR patients than in LPR patients, and miR-135a-5p, miR-144-3p, miR-424-5p, miR-451a, miR-634 and miR-1283 were lower in HPR patients than in LPR patients. ${ }^{46}$ Only one study investigated platelet maturity and found that miR-202-3p correlated negatively with platelet maturity. ${ }^{31}$

\section{miRs without Association to Platelet Function and Maturity}

miR-15a-5p, ${ }^{37}$ miR-23a, ${ }^{36}$ miR-146b, ${ }^{41}$ miR-107, ${ }^{37}$ miR$199,{ }^{36}$ miR-339-3p, ${ }^{37}$ miR-495-3p, ${ }^{37}$ miR-501-3p, ${ }^{39}$ miR584-5p, ${ }^{39}$ miR-1273h-3p, ${ }^{39}$ miR-nov-chr1, ${ }^{39}$ miR-novchr8 ${ }^{39}$ and miR-nov-chr $22^{39}$ did not show any association 
Table 5 Investigated microRNAs (miRs) and the corresponding association with platelet function and maturity across patient groups

\begin{tabular}{|c|c|c|c|}
\hline miRs & No. of studies ${ }^{\text {refs. }}$ & No. of patients & Findings \\
\hline Let-7d-3p & $1^{32}$ & 974 & $\begin{array}{l}\downarrow \text { correlation: ACS patients }(n=427) \\
\rightarrow: \text { ACS patients }(n=451) \\
\rightarrow: \text { CAD patients }(n=96)\end{array}$ \\
\hline miR-1 & $2^{33,45}$ & 27 & $\begin{array}{l}\rightarrow: \text { CAD patients }(n=15) \\
\uparrow: \text { SAD patients }(n=12)\end{array}$ \\
\hline miR-10a & $1^{32}$ & 249 & $\begin{array}{l}\uparrow \text { correlation: ACS patients }(n=153) \\
\rightarrow \text { : CAD patients }(n=96)\end{array}$ \\
\hline miR-15a-5p & $1^{36}$ & $<155^{\mathrm{a}}$ & $\rightarrow:$ CAD patients \\
\hline miR-15b-5p & $1^{32}$ & 1,127 & $\begin{array}{l}\uparrow \text { correlation: ACS patients }(n=153) \\
\uparrow \text { correlation: CAD patients }(n=96) \\
\rightarrow \text { : ACS patients }(n=878)\end{array}$ \\
\hline $\mathrm{miR}-20 \mathrm{~b}$ & $1^{40}$ & 125 & $\uparrow$ correlation: CAD patients \\
\hline miR-21 & $5^{32,33,39,42,43}$ & 1,358 & $\begin{array}{l}\downarrow: \text { ACS patients }(n=39) \\
\downarrow \text { correlation: ACS patients }(n=153) \\
\rightarrow \text { : ACS patients }(n=893) \\
\uparrow: \text { CAD patients }(n=115) \\
\rightarrow: \text { CAD patients }(n=158)\end{array}$ \\
\hline miR-23a & $1^{35}$ & 43 & $\rightarrow:$ CAD patients \\
\hline miR-24 & $1^{40}$ & 125 & $\uparrow$ correlation: CAD patients \\
\hline$m i R-25-5 p$ & $1^{32}$ & 1,127 & $\begin{array}{l}\uparrow \text { correlation: ACS patients }(n=153) \\
\rightarrow \text { : ACS patients }(n=878) \\
\rightarrow \text { CAD patients }(n=96)\end{array}$ \\
\hline miR-26a & $1^{35}$ & 43 & $\uparrow:$ CAD patients \\
\hline miR-27a-3p & $1^{43}$ & 115 & $\begin{array}{l}\uparrow \text { correlation: CAD patients } \\
\uparrow: \text { CAD patients }\end{array}$ \\
\hline miR-30b & $1^{40}$ & 125 & $\uparrow$ correlation: CAD patients \\
\hline miR-92a & $1^{34}$ & 50 & $\begin{array}{l}\rightarrow \text { : Claudication patients } \\
\uparrow \text { correlation: Claudication patients }(n=50)+\text { healthy } \\
\text { individual }(n=50)\end{array}$ \\
\hline miR-93 & $2^{32,40}$ & 374 & $\begin{array}{l}\uparrow \text { correlation: ACS patients }(n=153) \\
\uparrow \text { correlation: CAD patients }(n=96) \\
\rightarrow \text { : CAD patients }(n=125)\end{array}$ \\
\hline miR-96 & $2^{36,41}$ & $<188^{a}$ & $\begin{array}{l}\rightarrow: \text { ACS patients }(n=33) \\
\rightarrow \text { : CAD patients }(n<155)\end{array}$ \\
\hline miR-106a & $2^{40,43}$ & 240 & $\begin{array}{l}\uparrow: \text { CAD patients }(n=115) \\
\rightarrow \text { : CAD patients }(n=125)\end{array}$ \\
\hline miR-107 & $1^{36}$ & $<155^{\mathrm{a}}$ & $\rightarrow:$ CAD patients \\
\hline miR-126 & $5^{32,33,39,40,43}$ & 1,291 & $\begin{array}{l}\downarrow \text { correlation: ACS patients }(n=464) \\
\rightarrow \text { : ACS patients }(n=429) \\
\uparrow \text { correlation: CAD patients }(n=336) \\
\rightarrow: \text { CAD patients }(n=187)\end{array}$ \\
\hline miR-130a-5p & $1^{43}$ & 115 & $\begin{array}{l}\uparrow \text { correlation: CAD patients } \\
\uparrow: \text { CAD patients }\end{array}$ \\
\hline miR-133a & $1^{45}$ & 12 & $\uparrow:$ SAD patients \\
\hline miR-135a-5p & $1^{45}$ & 12 & $\begin{array}{l}\downarrow \text { correlation: SAD patients } \\
\downarrow: \text { SAD patients }\end{array}$ \\
\hline miR-142-5p & $1^{43}$ & 115 & $\begin{array}{l}\uparrow \text { correlation: CAD patients } \\
\uparrow: \text { CAD patients }\end{array}$ \\
\hline miR-144-3p & $1^{45}$ & 12 & $\downarrow:$ SAD patients \\
\hline $\mathrm{miR}-146 \mathrm{~b}$ & $1^{40}$ & 125 & $\rightarrow:$ CAD patients \\
\hline miR-150 & $4^{33,39,40,45}$ & 214 & \\
\hline
\end{tabular}


Table 5 (Continued)

\begin{tabular}{|c|c|c|c|}
\hline miRs & No. of studies ${ }^{\text {refs. }}$ & No. of patients & Findings \\
\hline & & & $\begin{array}{l}\rightarrow: \text { ACS patients }(n=15) \\
\uparrow \text { correlation: CAD patients }(n=62) \\
\rightarrow: \text { CAD patients }(n=125) \\
\downarrow: \text { SAD patients }(n=12)\end{array}$ \\
\hline miR-191 & $1^{40}$ & 125 & $\uparrow$ correlation: CAD patients \\
\hline miR-197 & $2^{32,40}$ & 1,252 & $\begin{array}{l}\uparrow \text { correlation: ACS patients }(n=153) \\
\uparrow \text { correlation: CAD patients }(n=125) \\
\rightarrow \text { : ACS patients }(n=878) \\
\rightarrow \text { : CAD patients }(n=96)\end{array}$ \\
\hline miR-199 & $1^{35}$ & 43 & $\rightarrow:$ CAD patients \\
\hline miR-202-3p & $1^{30}$ & 81 & $\downarrow$ correlation: CAD patients \\
\hline miR-204-5p & $2^{38,45}$ & 86 & $\begin{array}{l}\uparrow: \text { ACS patients }(n=74) \\
\downarrow: \text { SAD patients }(n=12) \\
\downarrow \text { correlation: SAD patients }(n=12)\end{array}$ \\
\hline miR-221 & $1^{42}$ & 39 & $\downarrow:$ ACS patients \\
\hline miR-223 & $9^{31,33,36,37,39-42,44}$ & $<572^{\mathrm{a}}$ & $\begin{array}{l}\downarrow \text { correlation: ACS patients }(n=116) \\
\downarrow: \text { ACS patients }(n=134) \\
\rightarrow \text { ACS patients }(n=15) \\
\uparrow \text { correlation: CAD patients }(n=187) \\
\rightarrow: \text { CAD patients }(n<215)\end{array}$ \\
\hline miR-324-5p & $1^{32}$ & 1,127 & $\begin{array}{l}\downarrow \text { correlation: ACS patients }(n=153) \\
\rightarrow \text { : ACS patients }(n=878) \\
\rightarrow: \text { CAD patients }(n=96)\end{array}$ \\
\hline miR-339-3p & $1^{36}$ & $<155^{\mathrm{a}}$ & $\rightarrow:$ CAD patients \\
\hline miR-345-5p & $1^{32}$ & 1,127 & $\begin{array}{l}\downarrow \text { correlation: ACS patients }(n=615) \\
\rightarrow: \text { ACS patients }(n=416) \\
\rightarrow \text { CAD patients }(n=96)\end{array}$ \\
\hline miR-365-3p & $1^{36}$ & $<155^{\mathrm{a}}$ & $\uparrow:$ CAD patients \\
\hline miR-410 & $1^{45}$ & 12 & $\uparrow:$ SAD patients \\
\hline miR-424-5p & $1^{45}$ & 12 & $\downarrow:$ SAD patients \\
\hline miR-451a & $1^{45}$ & 12 & $\downarrow:$ SAD patients \\
\hline miR-495-3p & $1^{36}$ & $<155^{\mathrm{a}}$ & $\downarrow:$ CAD patients \\
\hline miR-501-3p & $1^{38}$ & 10 & $\rightarrow:$ ACS patients \\
\hline miR-574-3p & $1^{32}$ & 974 & $\begin{array}{l}\downarrow \text { correlation: ACS patients }(n=435) \\
\rightarrow \text { : ACS patients }(n=443) \\
\rightarrow \text { : CAD patients }(n=96)\end{array}$ \\
\hline miR-584-5p & $1^{38}$ & 20 & $\rightarrow:$ ACS patients \\
\hline miR-589-5p & $1^{32}$ & 249 & $\begin{array}{l}\downarrow \text { correlation: ACS patients }(n=153) \\
\rightarrow \text { correlation: CAD patients }(n=96)\end{array}$ \\
\hline miR-634 & $1^{45}$ & 12 & $\downarrow:$ SAD patients \\
\hline miR-656 & $1^{45}$ & 12 & $\uparrow:$ SAD patients \\
\hline miR-671-3p & $1^{32}$ & 249 & $\begin{array}{l}\uparrow \text { correlation: ACS patients }(n=153) \\
\rightarrow \text { : CAD patients }(n=96)\end{array}$ \\
\hline miR-939-5p & $1^{32}$ & 1,127 & $\begin{array}{l}\uparrow \text { correlation: ACS patients }(n=153) \\
\rightarrow: \text { ACS patients }(n=878) \\
\rightarrow \text { : CAD patients }(n=96)\end{array}$ \\
\hline miR-1273h-3p & $1^{38}$ & 10 & $\rightarrow:$ ACS patients \\
\hline miR-1283 & $1^{45}$ & 12 & $\downarrow:$ SAD patients \\
\hline miR-1294 & $1^{32}$ & 153 & $\uparrow$ correlation: ACS patients \\
\hline miR-1908-5p & $1^{38}$ & 10 & $\downarrow:$ ACS patients \\
\hline
\end{tabular}

(Continued) 
Table 5 (Continued)

\begin{tabular}{|l|l|l|l|}
\hline miRs & No. of studies ${ }^{\text {refs. }}$ & No. of patients & Findings \\
\hline miR-3609 & $1^{32}$ & 153 & $\uparrow$ correlation: ACS patients \\
\hline miR-4732-3p & $1^{32}$ & 153 & $\uparrow$ correlation: ACS patients \\
\hline miR-nov1 & $1^{38}$ & 10 & $\rightarrow:$ ACS patients \\
\hline miR-nov8 & $1^{38}$ & 10 & $\rightarrow:$ ACS patients \\
\hline miR-nov22 & $1^{38}$ & 10 & $\rightarrow:$ ACS patients \\
\hline
\end{tabular}

Abbreviations: ACS, acute coronary syndrome; CAD, coronary artery disease; refs, reference number; SAD, symptomatic atherothrombotic diseases; $\uparrow$, higher value in patients with high platelet reactivity (HPR) vs. patients with low platelet reactivity (LPR); $\downarrow$, lower value in HPR vs. LPR patients; $\uparrow$ correlation, positive correlation; $\downarrow$ correlation, negative correlation; $\rightarrow$, no difference between HPR and LPR patients or no correlation. Note: After each finding, the subgroup is indicated in which the findings are reported. The findings correspond to all examined patients unless otherwise indicated.

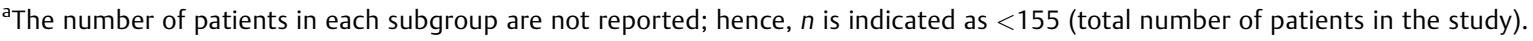

with platelet function or platelet maturity and were only investigated in one study (-Table 5 ).

\section{Discussion}

This systematic review included 16 studies examining the association between miRs and platelet function and maturity in patients with CVD, primarily ACS and stable CAD. We identified $44 \mathrm{miRs}$ associated with platelet function and 1 miR associated with platelet maturity. Ten miRs were investigated in more than one study and of these, 4 miRs were investigated in more than two studies, namely miR-223, miR126, miR-21 and miR-150.

\section{miRs and Platelet Function}

The expression level of miR-223 in relation to platelet function was investigated in 9 of the 16 included studies. Interestingly, different associations were reported across patient groups. $32,34,37,38,40-43,45$ The function and target of miR-223 have been investigated in some studies. ${ }^{27,48,49}$ Landry et al reported that the binding site of miR-223 is the 3' untranslated region (3' UTR) of the messenger RNA (mRNA) encoding for the P2Y12 receptor, known to be a mediator of granule secretion, platelet aggregation and thrombus formation. ${ }^{27}$ Additionally, Landry et al reported that miR-223 regulates the P2Y12 gene expression in both platelets and megakaryocytes. ${ }^{27}$ Furthermore, it was demonstrated that miR-223-deficient mice had higher platelet

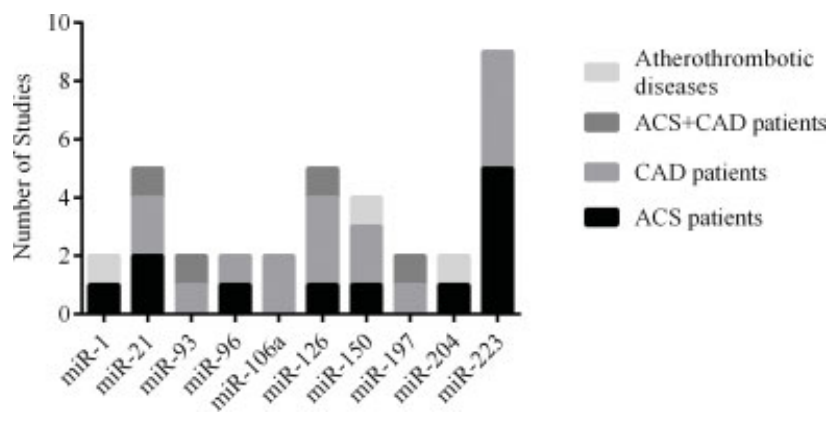

Fig. 2 Number of studies investigating microRNA (miRs). ACS, acute coronary syndrome; CADS, coronary artery disease. aggregation, larger thrombus formation and delayed clot retraction compared with wild-type mice. ${ }^{27}$ In addition, Fejes et al found that decreased miR-223 resulted in upregulated levels of P2Y12 mRNA. $^{48}$ Singh et al showed that the miR-223 level was higher in plaque material from the coronary arteries in unstable CAD patients than in stable CAD patients, and concluded that miR-223 may be a marker of plaque instability. ${ }^{49}$ Pan et al reported that miR-223 affects endothelial cells causing cell apoptosis and endothelial dysfunction. ${ }^{50}$ Kaur et al performed a recent review regarding the role of miRs to distinguish ACS patients from stable CAD patients. ${ }^{51}$ The authors identified three studies examining miR-223 and found miR-223 to be inconclusive as studies reported both up- and down-regulation. ${ }^{51}$ However, miR-223 may be a good marker of platelet function and ADP inhibitor monitoring due to its binding to the P2Y12 receptor. $^{27,52}$

The association between miR-126 and platelet function differed across patient groups as one study found miR-126 to be negatively correlated with platelet function ${ }^{33}$ in ACS patients, whereas three studies demonstrated a positive correlation in CAD patients. ${ }^{33,41,44}$ miR-126 has been shown to be present in endothelial cells contributing to the regulation of cell proliferation and vascular inflammation. ${ }^{53-55}$ In addition, miR-126 promotes the progression and function of endothelial progenitor cell. ${ }^{56}$ Furthermore, miR-126 promotes endothelial repair and plays a key role for restoration of normal vascular haemostasis and limiting atherosclerosis after vessel injury. ${ }^{57,58}$ These diverse roles may explain the different associations between miR-126 and platelet function reported across patient groups.

The findings regarding miR-21 and platelet function were inconclusive as two studies found miR-21 to be negatively associated with platelet function, ${ }^{33,43}$ one study found a positive association ${ }^{44}$ and three studies found no association. ${ }^{33,34,40}$ However, Kaur et al identified five studies examining miR-21 to distinguish ACS patients from CAD patients, and reported that all studies found miR-21 to be upregulated in ACS patients compared with CAD patients. ${ }^{51}$ Peng et al reported that P2Y12 mRNA was the predicted target site for miR-21. ${ }^{43}$ Furthermore, miR-21 has been showed to have 
various effects regarding the regulation and progression of atherosclerosis and to be present in different cell types, ${ }^{59-61}$ including endothelial cells ${ }^{62}$ and smooth muscle cells. ${ }^{63}$ In addition, the miR-21 expression was found to be highly upregulated in atherosclerotic plaques. ${ }^{60}$

Four studies investigated miR-150 and platelet function with unconvincing results with findings of either a weak or no association. ${ }^{33,34,41,46} \mathrm{Lu}$ et al found that miR-150 affects the regulation and enhancement of megakaryocytopoiesis by influencing the megakaryocyte-erythrocyte progenitor cells towards the megakaryocyte line. ${ }^{24}$ Tano et al suggested that miR-150 may also affect endothelial cells by regulation of endothelial repair process. ${ }^{64}$

\section{miRs and Platelet Maturity}

Only one of the included studies reported on platelet maturity in association with $\mathrm{miR}$ and found that miR-202-3p negatively correlated with MPV. ${ }^{31}$ miR-202-3p might inhibit platelet production by modulating the expression of genes important for cell formation including the $A B C G 4$ gene. ${ }^{31}$ In addition, $A B C G 4$ deficiency has been suggested to accelerate both atherosclerosis and thrombosis likely due to increased megakaryocyte proliferation and platelet production. ${ }^{31,65}$

\section{Normalization and Sample Preparation}

Comparisons across the included studies must be done with caution due to variation in the methods employed for miR examination. All studies used a normalization strategy to express miR levels, but different approaches were used. This may have influenced the results, as Faraldi et al have reported that different normalization strategies lead to different miR expression levels. ${ }^{47}$ In addition, the expression of miRs was investigated in different sample materials. All types of blood cells contribute to the concentration of miRs in the plasma and PPP samples, whereas platelets predominantly contribute to miRs in PRP. However, the different types of sample material may still be used to investigate miRs, though maybe with different purposes. To investigate specific mechanisms of miRs in platelets, PRP may be an ideal choice, but when investigating miRs as potential biomarkers, plasma or whole blood samples may be preferable due to less pre-analytical sample processing. Furthermore, differences in sample preparation and anticoagulants may also affect the quantity and quality of miR levels. ${ }^{66,67}$

Most of the included studies predefined the included patient population based on platelet function test, thereby making platelet function the exposure of interest. Thus, the expression level of miR was the related outcome of interest. However, to further investigate the potential of miRs as biomarkers, future studies should explore miRs as exposure and determine corresponding outcomes, such as platelet function and maturity or clinical thromboembolic events. There is a great potential for miRs as biomarkers due to the easy availability and stability in the circulation. However, as the analysis of miRs is expensive and time-consuming as well as dependent on many pre-analytic factors, only few studies examining miRs as biomarkers and their clinical applications are currently available. In addition, other factors may affect the levels of miRs, for example, comorbidity and medication. $^{68-72}$ More studies are therefore warranted to investigate the significance of these variables and the potential of miRs as biomarkers in a clinical context.

\section{Limitations}

Some limitations of the present systematic review have to be considered. We defined patients as having either HPR or LPR to make studies comparable as different subgroup definitions were employed across the included studies. As some studies distinguished HPR patients and LPR patients by the median or $50 \%$ of a platelet function test, some patients may therefore have platelet function within the spectrum of healthy individuals. Furthermore, the studies used different platelet function tests, which may not be directly comparable as they correlate rather poorly. ${ }^{15,73}$ The definitions of HPR and LPR differ between studies and no universal definition exists. This challenges comparison of results obtained across studies. In addition, the lack of standardization in the miR analyses may challenge the comparison between studies.

\section{Conclusion}

The present systematic review identified 45 miRs associated with platelet function or maturity in patients with CVD mainly suffering from ACS or stable CAD. However, the majority of miRs were only investigated in one study. Only miR-223, miR-126, miR-21 and miR-150 were investigated in more than two studies and among these, miR-223 and miR126 showed the most consistent results across patient groups. Based on the findings of the present systematic review, more data are needed on the potential use of miRs as biomarkers for platelet function and maturity in CVD patients.

\section{Funding}

We received financial support from the Department of Clinical Biochemistry, Aarhus University Hospital.

\section{Conflict of Interest}

None declared.

\section{References}

1 WHO. Cardiovascular diseases (CVDs). 2020. Available at: https:// www.who.int/news-room/fact-sheets/detail/cardiovascular-diseases-(cvds)

2 Sjögren M, Almgren P, Melander O. Polygenetic risk for coronary artery disease increases hospitalization burden and mortality. Int J Cardiol Heart Vasc 2019;24:100391

3 Adelborg K, Grove EL, Sundbøll J, Laursen M, Schmidt M. Sixteenyear nationwide trends in antithrombotic drug use in Denmark and its correlation with landmark studies. Heart 2016;102(23): 1883-1889

4 Freynhofer MK, Bruno V, Wojta J, Huber K. The role of platelets in athero-thrombotic events. Curr Pharm Des 2012;18(33): 5197-5214

5 Grove EL, Würtz M, Thomas MR, Kristensen SD. Antiplatelet therapy in acute coronary syndromes. Expert Opin Pharmacother 2015;16(14):2133-2147 
6 Gremmel T, Frelinger AL III, Michelson AD. Platelet physiology. Semin Thromb Hemost 2016;42(03):191-204

7 Halvorsen S, Andreotti F, ten Berg JM, et al. Aspirin therapy in primary cardiovascular disease prevention: a position paper of the European Society of Cardiology working group on thrombosis. J Am Coll Cardiol 2014;64(03):319-327

8 Patrono C, Morais J, Baigent C, et al. Antiplatelet agents for the treatment and prevention of coronary atherothrombosis. J Am Coll Cardiol 2017;70(14):1760-1776

9 Schrör K. Aspirin and platelets: the antiplatelet action of aspirin and its role in thrombosis treatment and prophylaxis. Semin Thromb Hemost 1997;23(04):349-356

10 Larsen SB, Grove EL, Neergaard-Petersen S, Würtz M, Hvas AM, Kristensen SD. Determinants of reduced antiplatelet effect of aspirin in patients with stable coronary artery disease. PLoS One 2015;10(05):e0126767

11 Snoep JD, Hovens MM, Eikenboom JC, van der Bom JG, Huisman MV. Association of laboratory-defined aspirin resistance with a higher risk of recurrent cardiovascular events: a systematic review and meta-analysis. Arch Intern Med 2007;167(15): 1593-1599

12 Krasopoulos G, Brister SJ, Beattie WS, Buchanan MR. Aspirin "resistance" and risk of cardiovascular morbidity: systematic review and meta-analysis. BMJ 2008;336(7637):195-198

13 Guirgis M, Thompson P, Jansen S. Review of aspirin and clopidogrel resistance in peripheral arterial disease. J Vasc Surg 2017;66 (05):1576-1586

14 Rocca B, Dragani A, Pagliaccia F. Identifying determinants of variability to tailor aspirin therapy. Expert Rev Cardiovasc Ther 2013;11(03):365-379

15 Würtz M, Grove EL. Interindividual variability in the efficacy of oral antiplatelet drugs: definitions, mechanisms and clinical importance. Curr Pharm Des 2012;18(33):5344-5361

16 Freynhofer MK, Gruber SC, Grove EL, Weiss TW, Wojta J, Huber K. Antiplatelet drugs in patients with enhanced platelet turnover: biomarkers versus platelet function testing. Thromb Haemost 2015;114(03):459-468

17 Cesari F, Marcucci R, Caporale R, et al. Relationship between high platelet turnover and platelet function in high-risk patients with coronary artery disease on dual antiplatelet therapy. Thromb Haemost 2008;99(05):930-935

18 Guthikonda S, Alviar CL, Vaduganathan M, et al. Role of reticulated platelets and platelet size heterogeneity on platelet activity after dual antiplatelet therapy with aspirin and clopidogrel in patients with stable coronary artery disease. J Am Coll Cardiol 2008;52 (09):743-749

19 McBane RD II, Gonzalez C, Hodge DO, Wysokinski WE. Propensity for young reticulated platelet recruitment into arterial thrombi. J Thromb Thrombolysis 2014;37(02):148-154

20 Baek D, Villén J, Shin C, Camargo FD, Gygi SP, Bartel DP. The impact of microRNAs on protein output. Nature 2008;455 (7209):64-71

21 Arroyo AB, de Los Reyes-García AM, Teruel-Montoya R, Vicente V, González-Conejero R, Martínez C. microRNAs in the haemostatic system: more than witnesses of thromboembolic diseases? Thromb Res 2018;166:1-9

22 Lim LP, Lau NC, Garrett-Engele P, et al. Microarray analysis shows that some microRNAs downregulate large numbers of target mRNAs. Nature 2005;433(7027):769-773

23 Rowley JW, Schwertz H, Weyrich AS. Platelet mRNA: the meaning behind the message. Curr Opin Hematol 2012;19(05):385-391

24 Lu J, Guo S, Ebert BL, et al. MicroRNA-mediated control of cell fate in megakaryocyte-erythrocyte progenitors. Dev Cell 2008;14 (06):843-853

25 Girardot M, Pecquet C, Boukour S, et al. miR-28 is a thrombopoietin receptor targeting microRNA detected in a fraction of myeloproliferative neoplasm patient platelets. Blood 2010;116 (03):437-445
26 Tran JQD, Pedersen OH, Larsen ML, et al. Platelet microRNA expression and association with platelet maturity and function in patients with essential thrombocythemia. Platelets 2020;31 (03):365-372

27 Landry P, Plante I, Ouellet DL, Perron MP, Rousseau G, Provost P. Existence of a microRNA pathway in anucleate platelets. Nat Struct Mol Biol 2009;16(09):961-966

28 Liberati A, Altman DG, Tetzlaff J, et al. The PRISMA statement for reporting systematic reviews and meta-analyses of studies that evaluate health care interventions: explanation and elaboration. PLoS Med 2009;6(07):e1000100

29 Martin JF, Trowbridge EA, Salmon G, Plumb J. The biological significance of platelet volume: its relationship to bleeding time, platelet thromboxane B2 production and megakaryocyte nuclear DNA concentration. Thromb Res 1983;32(05):443-460

30 The National Heart LaBlotNIoH. Study Quality Assessment Tools. 2013. Available at: https://www.nhlbi.nih.gov/health-topics/study-quality-assessment-tools

31 Li L, Wu F, Xie Y, et al. MiR-202-3p inhibits foam cell formation and is associated with coronary heart disease risk in a Chinese population. Int Heart J 2020;61(01):153-159

32 Xie W, Yin Q Zhang M, Li S, Chen S. Leukocyte miR-223-3p is not associated with altered platelet responses to clopidogrel in patients with coronary artery disease. Zhong Nan Da Xue Xue Bao Yi Xue Ban 2018;43(04):421-427

33 Becker KC, Kwee LC, Neely ML, et al. Circulating MicroRNA profiling in non-ST elevated coronary artery syndrome highlights genomic associations with serial platelet reactivity measurements. Sci Rep 2020;10(01):6169

34 Li S, Guo LZ, Kim MH, Han JY, Serebruany V. Platelet microRNA for predicting acute myocardial infarction. J Thromb Thrombolysis 2017;44(04):556-564

35 Binderup HG, Houlind K, Madsen JS, Brasen CL. Aspirin resistance may be identified by miR-92a in plasma combined with platelet distribution width. Clin Biochem 2016;49(15):1167-1172

36 Chen S, Qi X, Chen H, et al. Expression of miRNA-26a in platelets is associated with clopidogrel resistance following coronary stenting. Exp Ther Med 2016;12(01):518-524

37 Chen YC, Lin FY, Lin YW, et al. Platelet MicroRNA 365-3p expression correlates with high on-treatment platelet reactivity in coronary artery disease patients. Cardiovasc Drugs Ther 2019; 33(02):129-137

38 Chyrchel B, Totoń-Żurańska J, Kruszelnicka O, et al. Association of plasma miR-223 and platelet reactivity in patients with coronary artery disease on dual antiplatelet therapy: A preliminary report. Platelets 2015;26(06):593-597

39 Ding $\mathrm{T}$, Zeng X, Cheng B, et al. Platelets in acute coronary syndrome patients with high platelet reactivity after dual antiplatelet therapy exhibit upregulation of miR-204-5p. Ann Clin Lab Sci 2019;49(05):619-631

40 Jäger B, Stojkovic S, Haller PM, et al. Course of platelet miRNAs after cessation of P2Y12 antagonists. Eur J Clin Invest 2019;49 (08):e13149

41 Kaudewitz D, Skroblin P, Bender LH, et al. Association of MicroRNAs and YRNAs with platelet function. Circ Res 2016;118(03): 420-432

42 Shi R, Ge L, Zhou X, et al. Decreased platelet miR-223 expression is associated with high on-clopidogrel platelet reactivity. Thromb Res 2013;131(06):508-513

43 Peng L, Liu J, Qin L, et al. Interaction between platelet-derived microRNAs and CYP2C19*2 genotype on clopidogrel antiplatelet responsiveness in patients with ACS. Thromb Res 2017;157:97-102

44 Tang OJ, Lei HP, Wu H, et al. Plasma miR-142 predicts major adverse cardiovascular events as an intermediate biomarker of dual antiplatelet therapy. Acta Pharmacol Sin 2019;40(02): 208-215

45 Zhang YY, Zhou X, Ji WJ, et al. Decreased circulating microRNA223 level predicts high on-treatment platelet reactivity in 
patients with troponin-negative non-ST elevation acute coronary syndrome. J Thromb Thrombolysis 2014;38(01):65-72

46 Zufferey A, Ibberson M, Reny JL, et al. New molecular insights into modulation of platelet reactivity in aspirin-treated patients using a network-based approach. Hum Genet 2016;135(04):403-414

47 Faraldi M, Gomarasca M, Sansoni V, Perego S, Banfi G, Lombardi G. Normalization strategies differently affect circulating miRNA profile associated with the training status. Sci Rep 2019;9(01): 1584

48 Fejes Z, Póliska S, Czimmerer Z, et al. Hyperglycaemia suppresses microRNA expression in platelets to increase P2RY12 and SELP levels in type 2 diabetes mellitus. Thromb Haemost 2017;117 (03):529-542

49 Singh S, de Ronde MWJ, Kok MGM, et al. MiR-223-3p and miR$122-5 p$ as circulating biomarkers for plaque instability. Open Heart 2020;7(01):e001223

50 Pan Y, Liang $\mathrm{H}$, Liu $\mathrm{H}$, et al. Platelet-secreted microRNA-223 promotes endothelial cell apoptosis induced by advanced glycation end products via targeting the insulin-like growth factor 1 receptor. J Immunol 2014;192(01):437-446

51 Kaur A, Mackin ST, Schlosser K, et al. Systematic review of microRNA biomarkers in acute coronary syndrome and stable coronary artery disease. Cardiovasc Res 2020;116(06):1113-1124

52 Kahner BN, Shankar H, Murugappan S, Prasad GL, Kunapuli SP. Nucleotide receptor signaling in platelets. J Thromb Haemost 2006;4(11):2317-2326

53 Wang S, Aurora AB, Johnson BA, et al. The endothelial-specific microRNA miR-126 governs vascular integrity and angiogenesis. Dev Cell 2008;15(02):261-271

54 Fish JE, Santoro MM, Morton SU, et al. miR-126 regulates angiogenic signaling and vascular integrity. Dev Cell 2008;15(02): 272-284

55 Harris TA, Yamakuchi M, Ferlito M, Mendell JT, Lowenstein CJ. MicroRNA-126 regulates endothelial expression of vascular cell adhesion molecule 1. Proc Natl Acad Sci U S A 2008;105(05): 1516-1521

56 Meng Q Wang W, Yu X, et al. Upregulation of MicroRNA-126 contributes to endothelial progenitor cell function in deep vein thrombosis via its target PIK3R2. J Cell Biochem 2015;116(08): 1613-1623

57 Jansen F, Yang X, Hoelscher M, et al. Endothelial microparticlemediated transfer of MicroRNA-126 promotes vascular endothelial cell repair via SPRED1 and is abrogated in glucose-damaged endothelial microparticles. Circulation 2013;128(18):2026-2038

58 Schober A, Nazari-Jahantigh M, Wei Y, et al. MicroRNA-126-5p promotes endothelial proliferation and limits atherosclerosis by suppressing Dlk1. Nat Med 2014;20(04):368-376

59 Dai B, Wang F, Nie X, et al. The cell type-specific functions of miR21 in cardiovascular diseases. Front Genet 2020;11:563166
60 Raitoharju E, Oksala N, Lehtimäki T. MicroRNAs in the atherosclerotic plaque. Clin Chem 2013;59(12):1708-1721

61 Weber M, Baker MB, Moore JP, Searles CD. MiR-21 is induced in endothelial cells by shear stress and modulates apoptosis and eNOS activity. Biochem Biophys Res Commun 2010;393(04): 643-648

62 Suárez Y, Fernández-Hernando C, Pober JS, Sessa WC. Dicer dependent microRNAs regulate gene expression and functions in human endothelial cells. Circ Res 2007;100(08):1164-1173

$63 \mathrm{Ji}$ R, Cheng Y, Yue J, et al. MicroRNA expression signature and antisense-mediated depletion reveal an essential role of MicroRNA in vascular neointimal lesion formation. Circ Res 2007;100 (11):1579-1588

64 Tano N, Kim HW, Ashraf M. microRNA-150 regulates mobilization and migration of bone marrow-derived mononuclear cells by targeting Cxcr4. PLoS One 2011;6(10):e23114

65 Murphy AJ, Bijl N, Yvan-Charvet L, et al. Cholesterol efflux in megakaryocyte progenitors suppresses platelet production and thrombocytosis. Nat Med 2013;19(05):586-594

66 Farina NH, Wood ME, Perrapato SD, et al. Standardizing analysis of circulating microRNA: clinical and biological relevance. J Cell Biochem 2014;115(05):805-811

67 Zampetaki A, Mayr M. Analytical challenges and technical limitations in assessing circulating miRNAs. Thromb Haemost 2012; 108(04):592-598

68 Willeit P, Zampetaki A, Dudek K, et al. Circulating microRNAs as novel biomarkers for platelet activation. Circ Res 2013;112(04): 595-600

69 Kaudewitz D, Lee R, Willeit P, et al. Impact of intravenous heparin on quantification of circulating microRNAs in patients with coronary artery disease. Thromb Haemost 2013;110(03): 609-615

70 Gidlöf O, Andersson P, van der Pals J, Götberg M, Erlinge D. Cardiospecific microRNA plasma levels correlate with troponin and cardiac function in patients with ST elevation myocardial infarction, are selectively dependent on renal elimination, and can be detected in urine samples. Cardiology 2011;118(04): 217-226

71 Willeit P, Skroblin P, Moschen AR, et al. Circulating MicroRNA-122 Is associated with the risk of new-onset metabolic syndrome and type 2 diabetes. Diabetes 2017;66(02):347-357

72 Boeckel JN, Thomé CE, Leistner D, Zeiher AM, Fichtlscherer S, Dimmeler S. Heparin selectively affects the quantification of microRNAs in human blood samples. Clin Chem 2013;59(07): $1125-1127$

73 Grove EL, Hvas AM, Johnsen HL, et al. A comparison of platelet function tests and thromboxane metabolites to evaluate aspirin response in healthy individuals and patients with coronary artery disease. Thromb Haemost 2010;103(06):1245-1253 